\title{
Surowiec kaolinowy jako potencjalny material do syntezy zeolitu typu A
}

\section{Wprowadzenie}

Zeolity stanowią grupę minerałów będących uwodnionymi glinokrzemianami sodu, wapnia i potasu. Minerały te, $\mathrm{z}$ uwagi na swoje właściwości, wykorzystywane są w wielu dziedzinach inżynierii i ochrony środowiska, m. in. w: rafinacji ropy (Zhu i in. 2013), usuwaniu ze ścieków jonów amonowych (Liu i in. 2012) i metali ciężkich (Bajda i in. 2004; Merrikhpour i Jalali 2013) lub radionuklidów z wód kopalnianych (Chałupnik i in. 2013) oraz zanieczyszczeń substancjami ropopochodnymi (Bandura i in. 2015). Bardzo często wykorzystywane są również w separacji/adsorpcji gazów, takich jak $\mathrm{CO}_{2}$ (Walton i in. 2006; Wdowin i in. 2012), $\mathrm{SO}_{2}$ (Yi i in. 2012) lub gazowych form rtęci (Morency i in. 2000; Wdowin i in. 2014b, 2015).

Obok naturalnych nagromadzeń tego typu minerałów - głównie w postaci klinoptilolitu, phillipsytu, mordenitu duże - znaczenie praktyczne mają zeolity syntetyczne (Franus i Dudek 1999). Tradycyjnie zeolity syntetyczne powszechnie produkowane są z hydrożeli glinianu sodu i krzemionki (Breck 1974). Jednym z możliwych sposobów ich otrzymywania jest hydrotermalna konwersja popiołów lotnych (Franus i in. 2014; Wdowin i in. 2014a) lub perlitu (Pichór i in. 2014) z wodnym roztworem wodorotlenku sodu lub potasu w warunkach ściśle określonej temperatury, ciśnienia, czasu reakcji i stężenia substratów.

* Dr inż., Zakład Geotechnologii, Instytut Gospodarki Surowcami Mineralnymi i Energią PAN, Kraków; e-mail:wdowin@min-pan.krakow.pl 
Często również badania koncentrują się na syntezie zeolitów z surowców ilastych jako źródła krzemionki i glinu (Breck 1974; Chandrasekhar i Pramada 1999; Aderemi 2004; Ismael 2010).

Spośród wielu zeolitów syntetycznych duże znaczenie przemysłowe ma zeolit typu A (komercyjnie nazywany Linde-A). Decydują o tym jego właściwości molekularno-sitowe, jonowymienne i adsorpcyjne. Synteza takiego materiału w skali przemysłowej jest kosztowna, co ogranicza jego komercyjne zastosowanie (Miao i in. 2009).

Jedną z metod otrzymywania tego zeolitu jest wykorzystanie w tym celu surowca ilastego jakim jest kaolin, który od wielu lat stosuje się jako jeden z najbardziej uniwersalnych surowców mineralnych w wielu branżach przemysłu m.in. w przemyśle ceramicznym, papierniczym, gumowym, materiałów ogniotrwałych, polimerów, farb i lakierów i in. (Lewicka i Muzal 2000; Lewicka 2004). Przy stosunku molowym Si/Al bliskim 1, surowiec kaolinowy jest idealnym materiałem do syntezy zeolitu Na-A (Chandrasekhar $\mathrm{i}$ in. 1997).

W Polsce kaolin uzyskuje się głównie z kilku złóż znajdujących się w Niecce Bolesławieckiej (złoże słabozwięzłych piaskowców - Maria III oraz złoże piasków i piaskowców kwarcowych Osiecznica II) i Niecce Tomaszowskiej (złoża piasków i piaskowców Biała Góra oraz Grudzeń Las) (Lewicka 2004).

Celem pracy było określenie możliwości wykorzystania krajowych produktów kaolinowych uzyskiwanych ze złoża Maria III do syntezy materiałów zeolitowych. Badania te przeprowadzono ponieważ wykorzystanie w tym kierunku krajowego, szlamowanego surowca kaolinowego dotychczas nie było rozważane.

\section{Material badawczy}

Materiał wyjściowy wykorzystany do syntezy zeolitu stanowił surowiec ilasty (kaolin szlamowany) pozyskiwany ze słabozwięzłego piaskowca kaolinowego eksploatowanego ze złoża Maria III w Nowogrodźcu k. Bolesławca (Domka i in. 1999). Analizowany kaolin stanowi materiał wzbogacany, wysokogatunkowy pozyskiwany i sprzedawany do celów ceramicznych (w których wykorzystuje się również surowce skaleniowe) przez Kopalnię Surowców Mineralnych „SURMIN-KAOLIN” SA. Jego skład chemiczny przedstawia się następująco: $\mathrm{SiO}_{2}-51,5 \%, \mathrm{Al}_{2} \mathrm{O}_{3}-34,5 \%, \mathrm{Fe}_{2} \mathrm{O}_{3}-$ $0,54 \%, \mathrm{TiO}_{2}-0,54 \%, \mathrm{CaO}-0,08 \%, \mathrm{MgO}-0,12 \%, \mathrm{~K}_{2} \mathrm{O}-0,63 \%, \mathrm{Na}_{2} \mathrm{O}-0,01 \%$, LOI $-12 \%$. W swoim składzie mineralnym materiał ten posiada $80 \%$ kaolinitu, $9 \%$ illitu, $9 \%$ kwarcu oraz $2 \%$ pozostałych składników mineralnych. W składzie ziarnowym dominuje frakcja poniżej $15 \mu \mathrm{m} 98 \%$, w tym frakcja poniżej $2 \mu \mathrm{m}$ stanowi $59 \%$ (http://www.surmin-kaolin.com.pl).

Proces syntezy

Reakcję syntezy przeprowadzono według poniższego schematu: 


$$
\text { Kaolin } \stackrel{\text { kalcynacja }}{\text { czas, }} \text { Metakaolin }+x \mathrm{NaOH} \longrightarrow \text { zeolit }
$$

gdzie $x$ to stężenie $\mathrm{NaOH}$.

Warunki prowadzenia procesu przedstawiały się następująco: w pierwszym etapie przeprowadzono kalcynację kaolinu w temperaturze $800^{\circ} \mathrm{C}$ przez $12 \mathrm{~h}$, w wyniku czego otrzymano amorficzny, bardziej reaktywny produkt (metakaolin); następnie otrzymany materiał połączono z $3 \mathrm{~mol} \cdot \mathrm{dm}^{-3} \mathrm{NaOH}$ w stosunku 1,5:5, a reakcja przebiegała w temperaturze $100^{\circ} \mathrm{C}$ przez $3 \mathrm{~h}$.

W wyniku reakcji syntezy otrzymano zeolit syntetyczny typu A (Na-A). W skład jego szkieletu strukturalnego wchodzą tetraedry glinotlenowe $\left(\mathrm{AlO}_{4}\right)^{-5}$ i krzemotlenowe $\left(\mathrm{SiO}_{4}\right)^{-4}$, połączone ze sobą wspólnymi jonami tlenu. Dwadzieścia cztery tetraedry glinoi krzemotlenowe formują przestrzenne jednostki kubooktaedryczne, które są elementem występującym w budowie sieci krystalicznej m.in. zeolitów typu A, X, Y, fojazytu czy sodalitu.

Dla zeolitu typu A kubooktaedr składa się z 12 czworościanów $\left(\mathrm{SiO}_{4}\right)^{-4}$ i 12 czworościanów $\left(\mathrm{AlO}_{4}\right)^{-5}$, jak też odpowiedniej ilości kationów. Osiem połączonych ze sobą kubooktaedrów formuje przestrzenną strukturę zeolitu typu A (rys. 1). Za jego komórkę jednostkową przyjmuje się sześcian o długości boku $1,232 \mathrm{~nm}$ wyodrębniony z elementu struktury zeolitu przedstawionego na rysunku 1, płaszczyznami przechodzącymi przez środki kubooktaedrów (Ciembroniewicz 1993).

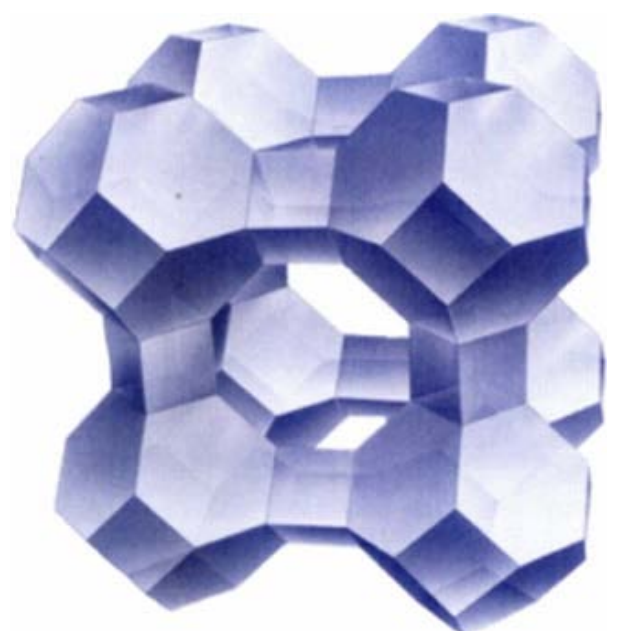

Rys. 1. Model przestrzennego połączenia kubooktaedrów w zeolicie typu A (http://www.molecularsieve.org)

Fig. 1. Model of spatial connection of cubooctahedrons in A type zeolite (http://www.molecularsieve.org) 


\section{Metodyka}

Na otrzymanym materiale zeolitowym przeprowadzono szereg badań mineralogicznych (XRD, SEM-EDS) i teksturalnych (powierzchnia właściwa BET, rozkład i objętość porów).

Rentgenowską analizę fazową (XRD) wykonano metodą proszkową stosując dyfraktometr rentgenowski Panalytical X'pert APD z goniometrem PW 3020 i lampą Cu oraz monochromatorem grafitowym. Analizy wykonano w zakresie kątowym od 5 do 652 theta. Do obróbki danych dyfrakcyjnych użyto oprogramowania X'Pert. Identyfikację faz mineralnych oparto na bazie danych JCPDS - ICDD (Joint Committee on Powder Diffraction Standards - The International Centre for Diffraction Data).

Do analiz z użyciem skaningowej mikroskopii elektronowej zastosowano mikroskop FEI QUANTA 200 FEG ze spektrometrem dyspersji energii EDS-EDAX.

Oznaczenie składu pierwiastkowego otrzymanego zeolitu Na-A wykonano metodą bezwzorcową na sekwencyjnym spektrometrze z dyspersją długości fali (WD-XRF) RIGAKU ZSX Primus II z lampą Rh $(4,0 \mathrm{~kW})$. Przed wykonaniem analizy rozdrobnioną próbkę homogenizowano $\mathrm{z}$ lepiszczem $\mathrm{w}$ młynku przez $5 \mathrm{~min}$, a następnie sprasowano do postaci pastylki o średnicy $30 \mathrm{~mm}$ z naciskiem $200 \mathrm{kN}$ przez dwie minuty. Analizy przeprowadzono w zakresie oznaczania pierwiastków od B do U (tj. pierwiastków o liczbie atomowej od 5 do 92), w atmosferze próżni.

Analizę termiczną przeprowadzono stosując aparat do analizy termicznej STA 449 F3 Jupiter Netzsch sprzężony z kwadrupolowym spektrometrem masowym QMS 403C Aeolos i spektrometrem FTIR Bruker.

Badania tekstury próbek skalnych przeprowadzono przy użyciu sorptomatu ASAP 2020M firmy Micromeritics. Dokonano oznaczeń następujących parametrów:

- $\mathrm{S}_{\mathrm{BET}}$ - powierzchnia właściwa $\left[\mathrm{m}^{2} / \mathrm{g}\right]$,

- Vp-objętość całkowita porów $\left[\mathrm{cm}^{3} / \mathrm{g}\right]$,

- D - średnia średnica porów [nm].

Właściwości teksturalne, takie jak powierzchnia właściwa, powierzchnia właściwa mikroporów, pomiar wielkości i rozkład porów w zależności od promienia, oznaczono na podstawie przebiegu izotermy adsorpcji/desorpcji par azotu w temperaturze $-194,85^{\circ} \mathrm{C}$. Wymienione parametry teksturalne badanych materiałów oznaczono po wcześniejszym odgazowaniu próbki w warunkach ściśle kontrolowanej temperatury $\left(250^{\circ} \mathrm{C}\right.$ przez $\left.24 \mathrm{~h}\right)$ i obniżonego ciśnienia $\left(10^{-3} \mathrm{hPa}\right)$. Powierzchnię właściwą oznaczono opierając się na teorii wielowarstwowej adsorpcji Braunauera-Emmetta-Tellera, tzw. BET przy $\mathrm{p} / \mathrm{p}_{0}$ pomiędzy 0,06 i 0,3 ( $\mathrm{p}, \mathrm{p}_{0}$ - ciśnienie równowagowe i ciśnienie par nasyconych azotem). Objętość porów Vp określono z objętości zaadsorbowanego azotu przy ciśnieniu $\mathrm{p} / \mathrm{p}_{0}=0,98$. Średnice porów Dp obliczono według wzoru $\mathrm{Dp}=4 \mathrm{Vp} / \mathrm{S}_{\mathrm{BET}}$. Rozkład objętości porów Rp wyliczono z ogólnego równania izotermy opartego na połączeniu zmodyfikowanego równania Kelvina i statystycznej grubości adsorbowanego filmu. 


\section{Wyniki}

\subsection{Charakterystyka mineralogiczna}

Badany zeolit Na-A należy do grupy tschernichitu. Klasyfikując go według wtórnych jednostek strukturalnych (SBU - second building unit) zeolit typu A zaliczany jest do grupy D4R. Obecność analizowanej fazy zeolitowej Na-A oznaczono opierając się na charakterystycznych dla tego minerału odległościach międzypłaszczyznowych $\mathrm{d}_{\mathrm{hkl}}=12,2 ; 8,66$; 7,08; 4,08; 3,70; $3,28 \AA$ (rys. 2). Krzywa dyfrakcyjna składu mineralnego wskazuje bardzo wyraźne refleksy pochodzące prawie w całości od zeolitu Na-A. Ilość czystego zeolitu określona metodą Rietvelda w badanym materiale wynosi 95\%. Zawiera on również bardzo niewielkie ilości kwarcu.

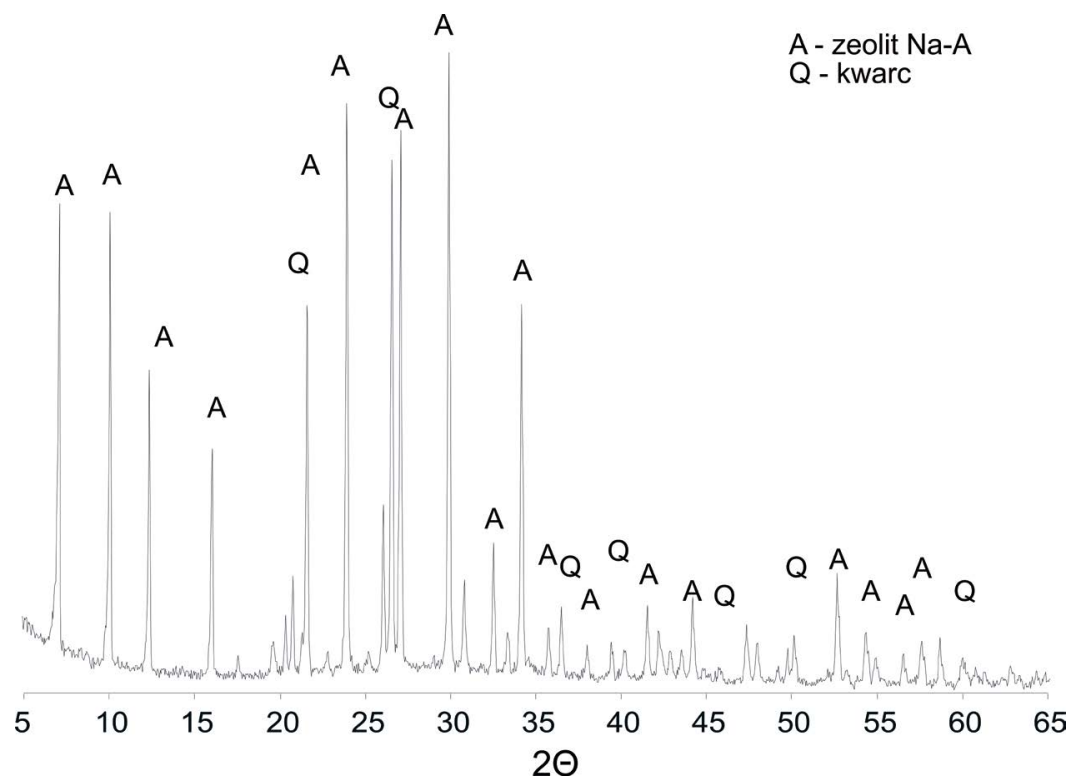

Rys. 2. Krzywa dyfrakcyjna składu mineralnego otrzymanego materiału zeolitowego typu A

Fig. 2. XRD diffraction pattern of the mineral composition of derived zeolite material A-type

Badania SEM-EDS pozwoliły określić morfologię badanego materiału. Minerał ten uformował idealne kostkowe kryształy charakterystyczne dla zeolitu Na-A (rys. 3).

Analiza termiczna (rys. 4) badanego zeolitu wskazała 12-procentowy ubytek masy związany z dehydratacją próbki podczas ogrzewania od temperatury pokojowej do temperatury około $400^{\circ} \mathrm{C}$. Natomiast analiza DTA wykazała obecność reakcji endotermicznych mających maksiumum efektu w temperaturach $200^{\circ} \mathrm{C}$ (związana z utratą wody zaadsorbowanej, śródwięźbowej) oraz $570^{\circ} \mathrm{C}$ (związana ze stopniowym uwalnianiem wody). 

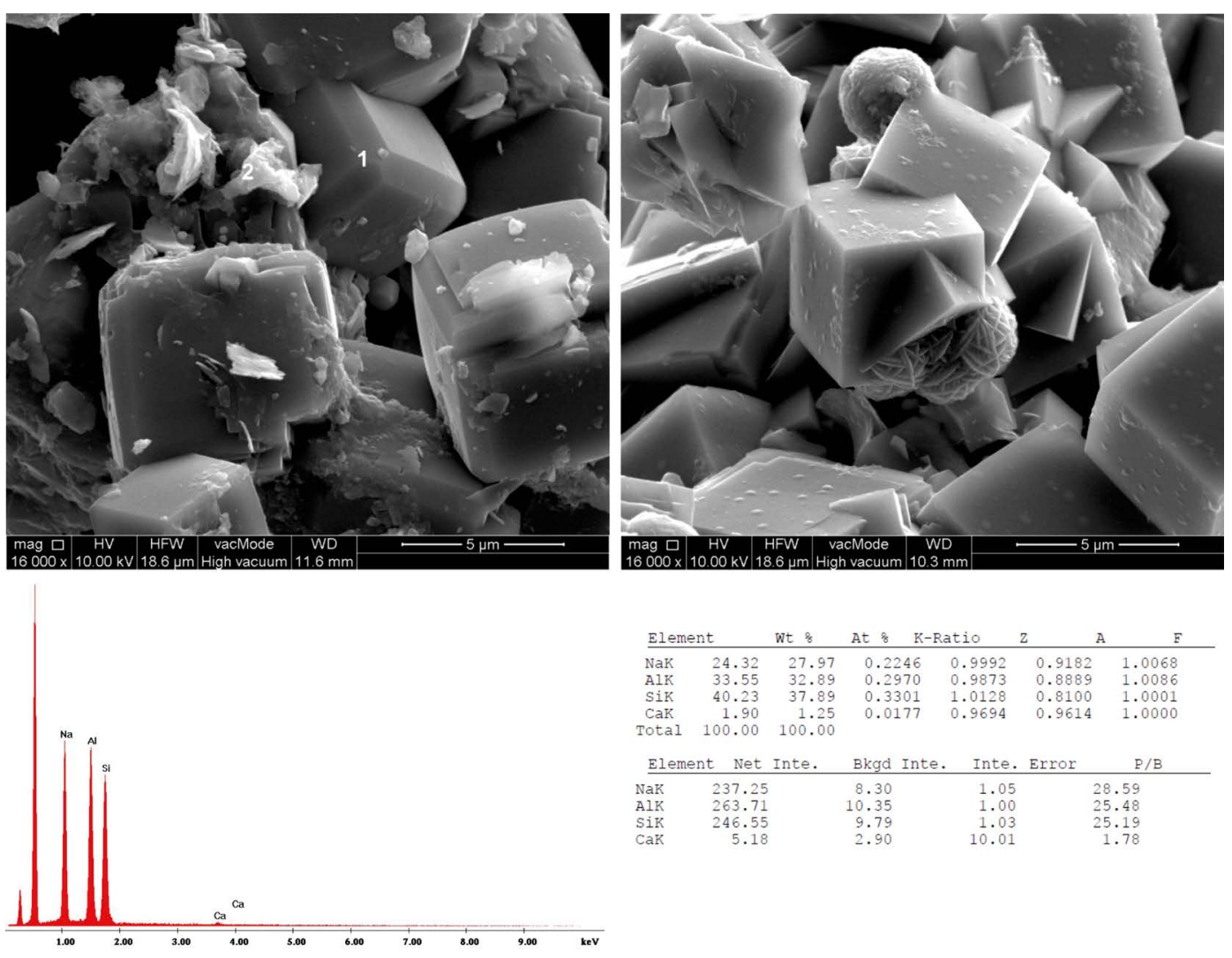

Analiza SEM-EDS z punkt $\mathbf{n r} 1$

Rys. 3. Mikrofotografie SEM-EDS otrzymanego materiału zeolitowego typu A

Fig. 3. SEM-EDS microphotographs of derived zeolite material A-type

\subsection{Analiza teksturalna}

Tabela 1 przedstawia najważniejsze parametry teskturalne badanego materiału zeolitowego, w którym wartość powierzchni właściwej BET w atmosferze azotu wyniosła zaledwie $4 \mathrm{~m}^{2} / \mathrm{g}$. Zeolit ten charakteryzuje się średnią średnicą porów $\sim 25 \mathrm{~nm}$. Ze względu na udział mikro-, mezo- i makroporów, zeolit ten można określić jako mikro-/mezoporowaty. Również stosunkowo duży udział w rozkładzie porów mają makropory.

Rozkład wielkości porów (rys. 5) dla zeolitu Na-A otrzymanego z kaolinu jest heterogeniczyny z dominacją porów o średnicy $3,5 \mathrm{~nm}$ oraz porów z zakresu $5-11 \mathrm{~nm}$, co potwierdza mezoporowatą naturę badanego materiału. 


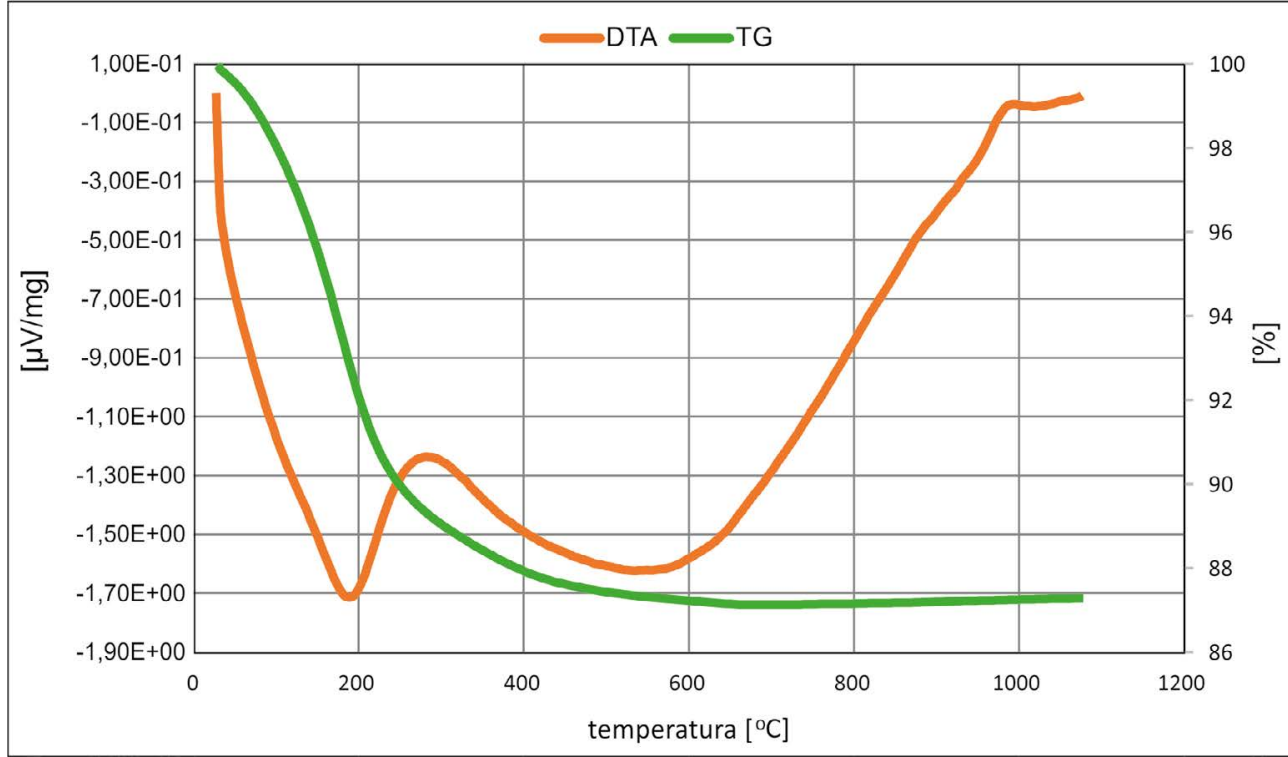

Rys. 4. Krzywe DTA/TG otrzymanego materiału zeolitowego typu A

Fig. 4. DTA/TG curves of derived zeolite materials A-type

Tabela 1. Parametry teskturalne otrzymanego materiału zeolitowego typu A

Table 1. Textural parameters of derived zeolite materials A-type

\begin{tabular}{|c|c|c|c|c|c|c|}
\hline Sorbent & $\begin{array}{c}\text { Powierzchnia } \\
\text { właściwa BET } \\
{\left[\mathrm{m}^{2} / \mathrm{g}\right]}\end{array}$ & $\begin{array}{c}\mathrm{D}_{\mathrm{p}}(4 \mathrm{~V} / \mathrm{A}) \\
{[\mathrm{nm}]}\end{array}$ & $\begin{array}{c}\mathrm{V}_{\mathrm{p}} \\
{\left[\mathrm{cm}^{3} / \mathrm{g}\right]}\end{array}$ & $\begin{array}{c}\mathrm{Rp} \\
\text { mikropory } \\
{[\%]}\end{array}$ & $\begin{array}{c}\mathrm{R}_{\mathrm{p}} \\
\text { mezopory } \\
{[\%]}\end{array}$ & $\begin{array}{c}\mathrm{R}_{\mathrm{p}} \\
\text { makropory } \\
{[\%]}\end{array}$ \\
\hline Na-A & 4 & 24,8 & 0,016 & 32,03 & 40,53 & 27,44 \\
\hline
\end{tabular}

Izotermy adsorpcji/desorpcji (rys. 6) posiadają pętlę histerezy wskazującą na kondensację kapilarną w mezoporach. Kształt pętli histerezy według klasyfikacji de Boera (1958) odpowiada typowi E, według klasyfikacji IUPAC - H3. Natomiast ze względu na kształt izoterm można je określić jako typ III/IV według IUPAC, co wskazuje na obecność porów typu „butelkowego”, czyli tzw. „kałamarza”, oraz sferycznych porów z otwartymi końcami i znacznymi przewężeniami wewnętrznymi (Klinik 2000). 


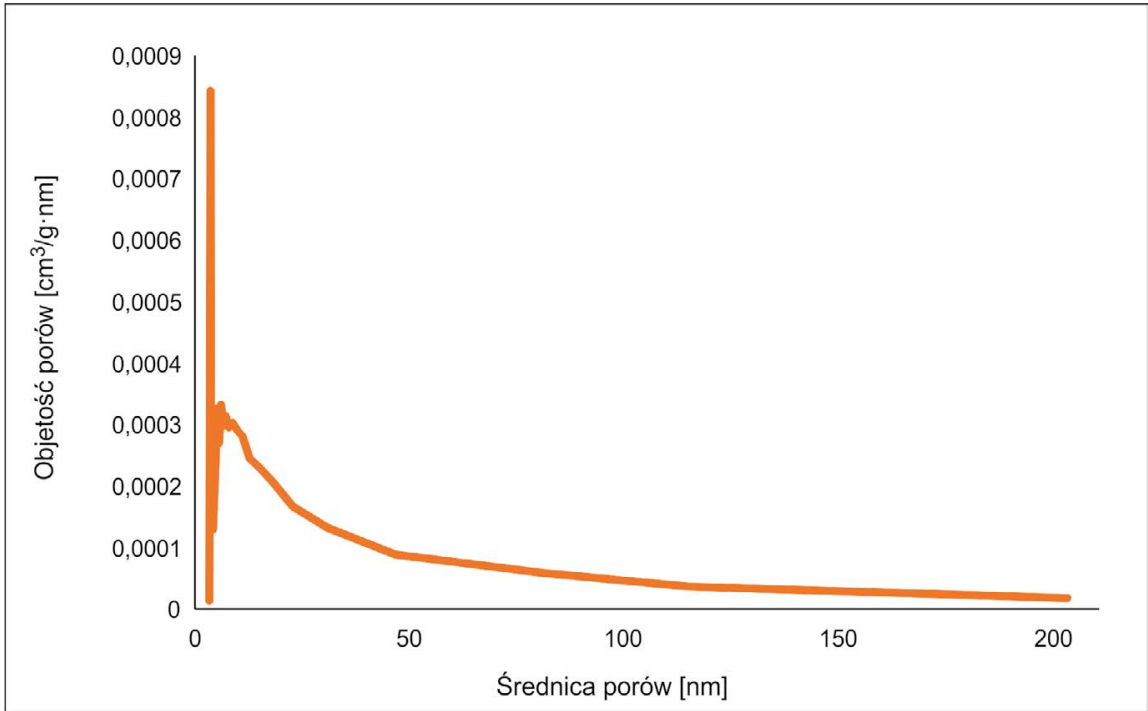

Rys. 5. Rozkład wielkości porów dla otrzymanego materiału zeolitowego typu A

Fig. 5. Pore size distribution of derived zeolite materials A-type

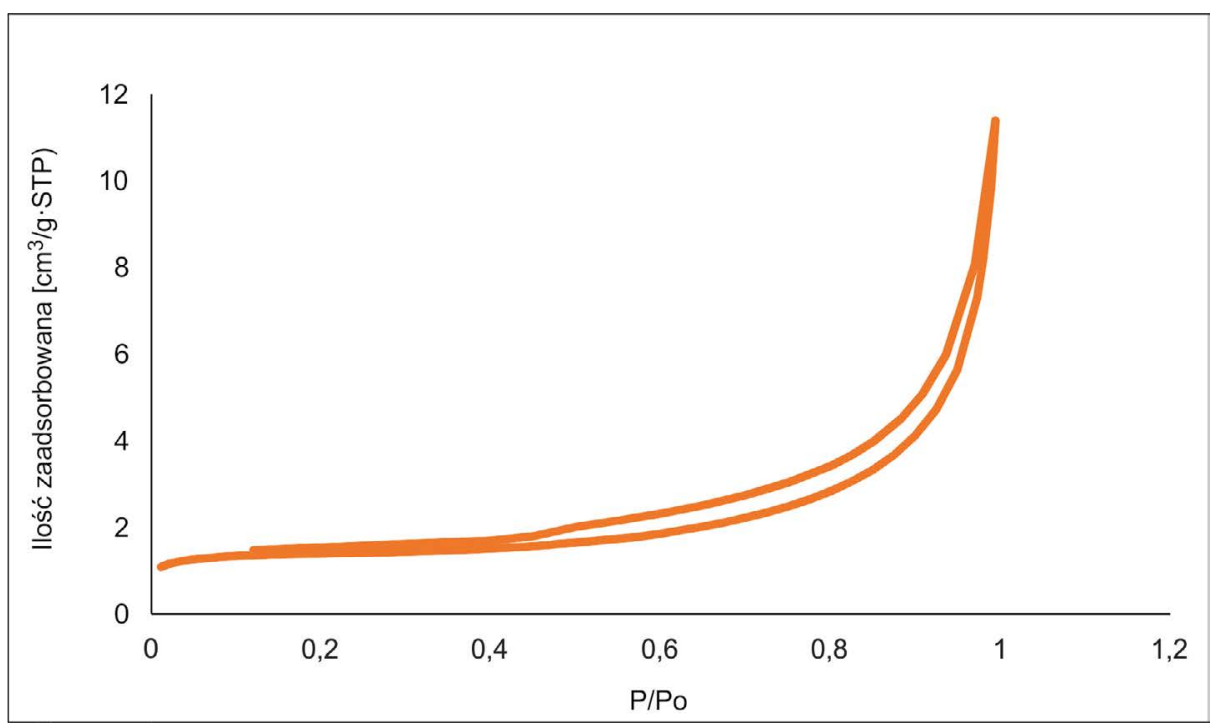

Rys. 6. Izotermy adsorpcji/desorpcji azotu dla otrzymanego materiału zeolitowego typu A

Fig. 6. Nitrogen adsorption/desorption isotherms of derived zeolite materials A-type 


\subsection{Charakterystyka chemiczna}

Analiza chemiczna powstałego w wyniku reakcji syntezy zeolitu typu Na-A wykazała następujący udział poszczególnych pierwiastków w przeliczeniu na tlenki: $\mathrm{SiO}_{2}-53,6 \%$, $\mathrm{Al}_{2} \mathrm{O}_{3}-35,4 \%, \mathrm{Fe}_{2} \mathrm{O}_{3}-0,945 \%, \mathrm{CaO}-1,17 \%, \mathrm{MgO}-0,125 \%, \mathrm{Na}_{2} \mathrm{O}-6 \%, \mathrm{~K}_{2} \mathrm{O}-0,876 \%$, $\mathrm{SO}_{3}-0,058 \%, \mathrm{NiO}-0,0065 \%, \mathrm{CuO}-0,0067 \%, \mathrm{TiO}_{2}-0,979 \%, \mathrm{P}_{2} \mathrm{O}_{5}-0,456 \%, \mathrm{MnO}-$ 0,0133\%, $\mathrm{ZnO}-0,0068 \%, \mathrm{SrO}-0,213 \%, \mathrm{Y}_{2} \mathrm{O}-0,0010 \%, \mathrm{ZrO}_{2}-0,0196 \%, \mathrm{Cr}_{2} \mathrm{O}_{3}-0,0218 \%$, $\mathrm{Ga}_{2} \mathrm{O}_{3}-0,0039 \%, \mathrm{Rb}_{2} \mathrm{O}-0,0083 \%, \mathrm{Nb}_{2} \mathrm{O}_{5}-0,0040 \%, \mathrm{PbO}-0,0961 \%, \mathrm{ThO}_{2}-0,0071 \%$. Stosunek $\mathrm{SiO}_{2} / \mathrm{Al}_{2} \mathrm{O}_{3}$ wynosi $1,51 \mathrm{i}$ jest niemal niezmieniony w porównaniu do materiału wyjściowego (kaolinu) - 1,49. Wynika $\mathrm{z}$ tego, że reakcja syntezy nie zmieniła zasadniczo składu chemicznego (wzrosła jedynie ilość sodu), zmienił się natomiast skład mineralny, tj. struktura badanego materiału.

\subsection{Wstępne testy adsorpcji $\mathrm{CO}_{2}$}

Dla otrzymanego materiału Na-A przeprowadzono wstępne testy jego przydatności jako sorbentu $\mathrm{CO}_{2}$. W tabeli 2 porównano wyniki obliczeń powierzchni właściwej wyznaczonej $\mathrm{z}$ izoterm adsorpcji azotu i ditlenku węgla.

Tabela 2. Powierzchnia właściwa dla Na-A oznaczona w atmosferze azotu i ditlenku węgla

Table 2. The specific surface area for Na-A determined under nitrogen and carbon dioxide atmosphere

\begin{tabular}{|c|c|}
\hline & Na-A \\
\hline $\mathrm{SBET}$ & 4,42 \\
\hline $\mathrm{SCO}_{2} 0^{\circ} \mathrm{C}$ & 403,9 \\
\hline $\mathrm{SCO}_{2} 25^{\circ} \mathrm{C}$ & 392,4 \\
\hline
\end{tabular}

Badania teksturalne wykazały, że powierzchnia właściwa badanego zeolitu w atmosferze $\mathrm{CO}_{2}$ wzrasta stukrotnie z $4 \mathrm{~m}^{2} / \mathrm{g}$ do $400 \mathrm{~m}^{2} / \mathrm{g}$. Jest to związane $\mathrm{z}$ tym, że azot ma więk-

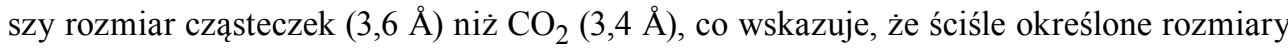
kanałów tego zeolitu są odpowiednie dla cząsteczek ditlenku węgla. W związku z tym stanowi potencjalny materiał sorpcyjny dla $\mathrm{CO}_{2}$.

\section{Potencjalne zastosowania}

Zeolit typu A, z uwagi na określony rozmiar kanałów i komór znalazł szerokie zastosowanie jako selektywny adsorbent wykazujący właściwości sitowo-cząsteczkowe. W porównaniu do innych zeolitów ten typ charakteryzuje duża pojemność adsorpcyjna, jak też 
duża szybkość adsorpcji. Otrzymany w pracy zeolit Na-A komercyjnie nazywany jest 4A, a jego wzór ogólny przedstawia się następująco $\mathrm{Na}_{2} \mathrm{O} \cdot \mathrm{Al}_{2} \mathrm{O}_{3} \cdot 2 \mathrm{SiO}_{2} \cdot \mathrm{xH}_{2} \mathrm{O}($ Ciembroniewicz 1993).

Rozważając konkretne zastosowania materiał zeolitowy typu A jest powszechnie wykorzystywany do usuwania wielu rodzajów zanieczyszczeń w technologiach środowiskowych. Według doniesień literaturowych materiał tego typu może stanowić wysokiej klasy sorbent mineralny wykorzystywany do usuwania jonów amonowych z roztworów wodnych (Kwakye-Awuah i in. 2014; Zhao i in. 2010) oraz metali ciężkich (Rondón i in. 2013; Mehdizadeh i in. 2014; Kyzioł-Komosińska i in. 2015).

Wiele badań koncentruje się również nad wykorzystaniem zeolitów typu A do adsorpcji różnego rodzaju gazów m.in. $\mathrm{NO}_{\mathrm{x}}, \mathrm{SO}_{\mathrm{x}}, \mathrm{CO}_{2}$ (Siriwardane i in. 2001; Du i in. 2014).

Interesującym kierunkiem wykorzystania wydaje się być zastosowanie zeolitu typu A w rafinacji ropy i usuwaniu radionuklidów z różnego rodzaju mediów (Park i in. 2010).

\section{Wnioski}

Czysty zeolit Na-A otrzymano w reakcji hydrotermalnej kaolinu uzyskiwanego z krajowych surowców. Dyfraktogram składu mineralnego wykazał bardzo wysoki stopień krystalizacji badanego materiału. W składzie mineralnym produktów reakcji syntezy występuje głównie zeolit Na-A (95\%) oraz niewielkie ilości kwarcu (5\%). Zeolit charakteryzuje się bardzo dobrze wykształconą formą morfologiczną (kubiczne kryształy). Podobne, dobrze uformowane kryształy zeolitu Na-A, uzyskali inni autorzy wykorzystujący do syntezy tego zeolitu jako substratu kaolin (Miao i in. 2009; Mostafa i in. 2011). W związku z tym można wnioskować, że surowiec kaolinowy uzyskiwany ze złoża zwięzłych piaskowców Maria III nadaje się do syntezy materiałów zeolitowych o dobrze wykształconych formach morfologicznych. Parametry powierzchniowe obliczone w atmosferze azotu i $\mathrm{CO}_{2}$ wskazują na możliwość wykorzystania badanego materiału jako sorbentu ditlenku węgla.

Badania zrealizowano w ramach prac statutowych IGSMiE PAN

\section{LITERATURA}

Aderemi, B.O. 2004. Preliminary Studies on Synthesis of Zeolites from Local Clay. Nigerian Journal of Scientific Research 4(2), s. 7-12.

Bajda i in. 2004 - Bajda, T., Franus, W., Manecki, A., Manecki, M., Mozgawa, W. i Sikora, M. 2004. Sorption of heavy metals on natural zeolite and smectite-zeolite shale from the Polish Flysch Carpathians. Polish Journal of Environmental Studies 13 (Suppl III), s. 7-10.

Bandura i in. 2015 - Bandura, L., Franus, M., Józefaciuk, G. i Franus, W. 2015. Synthetic zeolites from fly ash as effective mineral sorbents for land-based petroleum spills cleanup. Fuel 147, s. 100-107.

Breck, D.W. 1974. Zeolite Molecular sieves- Structure, Chemistry and uses. New York, John Wiley. 
Chałupnik i in. 2013 - Chałupnik, S., Franus, W., Wysocka, M. i Gzyl, G. 2013. Application of zeolites for radium removal from mine water. Environmental Sciences Pollution \& Research 20(11), s. 7900-7906.

Chandrasekhar i in. 1997 - Chandrasekhar, S., Raghavan, P., Sebastian, G. i Damodaran, A.D. 1997. Brightness improvement studies on kaolin based zeolite 4A. Applied Clay Science 12, s. 221-231.

Chandrasekhar, S. i Pramada, P.N. 1999. Investigation on the Synthesis of Zeolite NaX from Kerala Kaolin. Journal of Porous Materials 6(4), s. 283-297.

de Boer, J.H. 1958. The Structure and Properties of Porous Materials. (red. D.H. Everett and F.S. Stone), Butterworth, London 68.

Ciembroniewicz, A. 1993. Kinetyka adsorpcji gazów w zeolitach i sitach cząsteczkowych typu A. Zeszyty Naukowe AGH, z. 22, Kraków.Domka i in. 1999 - Domka L., Foltynowicz Z., Urbaniak W., Wienskowski K. 1999. Modyfikowane kaoliny - napełniaczne PCW. Fizykochemiczne Problemy Mineralurgii 33, s. 23-32.

Du i in. 2014 - Du, T., Liu, Y-J, Xiao, P.,Che, S. i Wang H-M. 2014. Preparation of zeolite NaA for $\mathrm{CO}_{2}$ capture from nickel laterite residue. International Journal of Minerals, Metallurgy, and Materials 21(8), s. 820-82.

Franus, W. i Dudek, K. 1999. Clay minerals and clinoptilolite from the Variegated Shales Formation in the Skole Unit, Polish Flysch Carpathians. Geologica Carpathica 50, s. 23-24.

Franus i in. 2014 - Franus, W., Wdowin, M. i Franus, M. 2014. Synthesis of zeolites for fly ash development. Environmental Monitoring and Assessment 186(9), s. 5721-5729.

http://www.surmin-kaolin.com.pl

http://www.molecularsieve.org

Ismael, I.S. 2010. Synthesis and characterization of zeolite X obtained from kaolin for adsorption of Zn(II). Chinese Journal of Geochemistry 29, s. 130-136.

Klinik, J. 2000. Tekstura porowatych ciat statych. AGH - Ośrodek Edukacji Niestacjonarnej, Kraków.

Kwakye-Awuah i in. 2014 - Kwakye-Awuah, B., Labik, L.K., Nkrumah, I. i Williams, C. 2014. Removal of ammonium ions by laboratory-synthesized zeolite linde type A adsorption from water samples affected by mining activities in Ghana. Journal of Water and Health (1), s. 151-160.

Kyzioł-Komosińska i in. 2015 - Kyzioł-Komosińska, J., Rosik-Dulewska, C. i Franus, M., Antoszczyszyn-Szpicka P., Czupioł J., Krzyżewska I. 2015. Sorption Capacities of Natural and Synthetic Zeolites for Cu(II). Polish Journal of Environmental Studies 3(24), s. 1111-1123.

Lewicka, E. 2004. Gospodarka surowcami kaolinowymi w Polsce. Wydawnictwo IGSMiE PAN, Kraków (Surowce mineralne Polski (Surowce skalne) Ney, R. red.).

Lewicka, E. i Muzal, Z. 2000. Tendencje zapotrzebowania na rynku kaolinu w Polsce i na świecie w. Aktualia i perspektywy gospodarki surowcami mineralnymi pt. Dekada w gospodarce surowcami mineralnymi i jej oblicze u progu XXI wieku. X Międzynarodowa konferencja Mąchocice-Ameliówka, 14-16 listopad 2000, Kraków.

Liu i in. 2012 - Liu, H., Peng, S., Shu, L., Chen, T., Bao, T. i Frost, R.L. 2012. Effect of $\mathrm{Fe}_{3} \mathrm{O}_{4}$ addition on removal of ammonium by zeolite NaA. Journal of Colloid Interface Science 390/1, s. 204-210.

Mehdizadeh i in. 2014 - Mehdizadeh, S., Sadjadi, S., Ahmadi, S.J. i Outokesh, M. 2014. Removal of heavy metals from aqueous solution using platinum nanopartcles/Zeolite-4A. Journal of Environmental Health Science and Engineering 2014, s 12:7, doi:10.1186/2052-336X-12-7.

Merrikhpour, H. i Jalali, M. 2013. Comparative and competitive adsorption of cadmium, copper, nickel, and lead ions by Iranian natural zeolite. Clean Technologies and Environmental Policy 15, s. 303-316.

Miao i in. 2009 - Miao, Q., Zhou, Z., Yang, J., Lu, J., Yan, S. i Wang, J. 2009. Synthesis of NaA zeolite from kaolin source. Frontiers of Chemical Science and Engineering 3(1), s. 8-11.

Morency i in. 2000 - Morency, J.R., Panagiotou, T. i Senior, C.L. 2000. Laboratory Duct Injection of a Zeolite-Based Mercury Sorbent. Presented at the Annual Meeting of the Air \& Waste Management Association, Salt Lake City, UT, June 2000

Mostafa i in. 2011 - Mostafa, A.A., Youssef, H.F., Sorour, M.H., Tewfik, S.R. i Shalaan, H.F. 2011. Utilization of Egyptian kaolin for Zeolite-A Preparation and Performance Evaluation. $20112^{\text {nd }}$ International Conference on Environmental Science and Technology, IPCBEE vol. 6 (2011) IACSIT Press, Singapore.

Park i in. 2010 - Park, H.S., Kim, I.T., Cho, Y.J., Son, M.S. i Eun, H.C. 2010. Removal behavior of Cs from molten salt by using zeolitic materials. Journal of Radioanalytical and Nuclear Chemistry 283(2), s. 267-272.

Pichór i in. 2014 - Pichór, W., Mozgawa, W., Król, M. i Adamczyk, A. 2014. Synthesis of the zeolites on the lightweight aluminosilicate fillers. Materials Research Bulletin 49(12), s. 210-215. 
Rondón i in. 2013 - Rondón, W., Freire, D., de Benzo, Z., Sifontes, A.B., González, Y., Valero, M. i Brito, J.L. 2013. Application of 3A Zeolite Prepared from Venezuelan Kaolin for Removal of $\mathrm{Pb}$ (II) from Wastewater and Its Determination by Flame Atomic Absorption Spectrometry. American Journal of Analytical Chemistry 4, s. 584-593.

Siriwardane i in. 2001 - Siriwardane, R.V., Shen, M.S., Fisher, E.P. i Poston, J.A. 2001. Adsorption of CO 2 on Molecular Sieves and Activated Carbon. Energy \& Fuels 15(2), s. 279-284.

Walton i in. 2006 - Walton, K.S., Abney, M.B. i Douglas, L.M. 2006. $\mathrm{CO}_{2}$ adsorption in Y and X zeolites modified by alkali metal cation exchange. Microporous and Mesoporous Materials 91, s. 78-84.

Wdowin i in. 2012 - Wdowin, M., Franus, W. i Panek, R. 2012. Preliminary results of usage possibilities of carbonate and zeolitic sorbents in $\mathrm{CO}_{2}$ capture. Fresenius Environmental Bulletin 21(12), s. 3726 -3734.

Wdowin i in. 2014 a - Wdowin, M., Franus, M., Panek, R., Badura, L. i Franus, W. 2014a. The conversion technology of fly ash into zeolites. Clean Technologies and Environmental Policy 16(6), s. 1217-1223,

Wdowin i in. 2014b - Wdowin, M., Wiatros-Motyka, M.M., Panek, R., Stevens, L.A., Franus, W. i Snape, C.E. 2014b. Experimental study of mercury removal from exhaust gases. Fuel 128, s. 451-457.

Wdowin i in. 2015 - Wdowin, M., Baran, P., Panek, R., Zarębska, K. i Franus, W. 2015. Analiza możliwości oczyszczania gazów wylotowych z $\mathrm{HgO}$ i $\mathrm{CO}_{2}$ na zeolitach syntetycznych z popiołów lotnych. Rocznik Ochrony Środowiska 2(17), s. 1306-1319.

Yi i in. 2012 - Yi H., Deng, H., Tang, X., Yu, Q., Zhou, X. i Liu, H. 2012. Adsorption equilibrium and kinetics for $\mathrm{SO}_{2}, \mathrm{NO}, \mathrm{CO}_{2}$ on zeolites FAU and LTA. Journal of Hazardous Materials 15(203-204), s. 111-117.

Zhao i in. 2010 - Zhao, Y., Zhang, B., Zhang, X., Wang, J., Liu, J. i Chen, R. 2010. Preparation of highly ordered cubic NaA zeolite from halloysite mineral for adsorption of ammonium ions. Journal of Hazardous Materials $178(1-3)$, s. 658-64.

Zhu i in. 2013 - Zhu, J., Meng, X. i Xiao, F. 2013. Mesoporous zeolites as efficient catalysts for oil refining and natural gas conversion. Frontier of Chemical Sciences and Engineering 7(2), s. 233-248.

\title{
SUROWIEC KAOLINOWY JAKO POTENCJALNY MATERIAŁ DO SYNTEZY ZEOLITU TYPU A
}

\author{
Słowa kluczowe \\ reakcja syntezy, kaolin, Na-A, charakterystyka mineralogiczno-chemiczna, \\ badania teksturalne
}

Streszczenie

W pracy przedstawiono możliwość uzyskania materiału zeolitowego typu A z naturalnych surowców ilastych. Materiał wykorzystany do syntezy stanowił wysokiej klasy kaolin pozyskiwany dla celów ceramicznych z piaskowca kaolinowego ze złoża Maria III k. Bolesławca. Surowiec kaolinowy poddano szeregom reakcji celem otrzymania zeolitu typu A. W pierwszym etapie materiał kalcynowano celem uzyskania amorficznego, bardziej reaktywnego produktu (metakaolinu). Następnie metakolin poddano reakcji hydrotermalnej ( $\mathrm{w}$ temperaturze $100^{\circ} \mathrm{C}$ ), gdzie materiał ten połączono $\mathrm{z}$ roztworem wodnym $3 \mathrm{~mol} \cdot \mathrm{dm}^{-3}$ wodorotlenu sodu. W wyniku reakcji otrzymano zeolit Na-A, który scharakteryzowano stosując metody mineralogiczne (XRD, SEM-EDS, DTA/TG), chemiczne (XRF) i teksturalne (ASAP). Badania XRD wykazały, że otrzymany produkt stanowi wysokiej czystości zeolit typu A, gdzie udział fazy zeolitowej w otrzymanym materiale wyniósł (95\% wt.), resztę stanowił kwarc. Analizy morfologii ziaren (SEM) potwierdziły dobrą krystalizację zeolitu, gdzie materiał ten formuje bardzo dobrze wykształcone kubiczne kryształy. Powierzchnia właściwa (w badaniach tek- 
sturalnych) oznaczona w atmosferze azotu wyniosła $4 \mathrm{~m}^{2} / \mathrm{g}$. Rozkład wielkości porów wykazał, że zeolit ten ma charakter mikro- i mezoporowaty z dominującym udziałem porów o średnicy 3,5 ̊. Celem określenia przydatności badanego materiału zeolitowego do sorpcji ditlenku węgla przeprowadzono wstępne testy, polegające na określeniu powierzchni właściwej w atmosferze $\mathrm{CO}_{2}$, w temperaturach 0 i $25^{\circ} \mathrm{C}$. W badaniach tych otrzymano intersujące wyniki, ponieważ powierzchnia właściwa $\mathrm{w}$ atmosferze $\mathrm{CO}_{2}$ dla każdej badanej temperatury wyniosła około $400 \mathrm{~m}^{2} / \mathrm{g}$. Wynik ten wskazuje na bardzo dobrą selektywność otrzymanego materiału względem $\mathrm{CO}_{2}$, przez co zeolit Na-A powinien być poddany dalszym analizom celem oszacowania jego przydatności pod kątem wychwytywania ditlenku węgla. Otrzymane wyniki syntezy i charakterystyki zeolitu Na-A wskazują na możliwość wykorzystania krajowego surowca kaolinowego do otrzymywania wysokiej jakości zeolitu typu A.

\section{RAW KAOLIN AS A POTENTIAL MATERIAL FOR THE SYNTHESIS OF A-TYPE ZEOLITE}

$$
\text { Keywords }
$$

synthesis reaction, kaolin, $\mathrm{Na}-\mathrm{A}$, mineralogical-chemical characteristics, textural investigations

\section{Abstract}

The paper presents the obtaining possibility of type A zeolite material from natural clays. The material used for the synthesis was a high-quality kaolin extracted for ceramic needs derived from kaolin sandstones of Maria III deposits near Boleslawiec. Raw kaolin was subjected to a series of synthesis reactions in order to obtain zeolite A. In the first stage a tested material was calcined in order to obtain an amorphous, more reactive product (metakaolin). Next, metakolin was hydrothermally reacted (at $100^{\circ} \mathrm{C}$ ) where the material was combined with the aqueous solution of $3 \mathrm{~mol} \cdot \mathrm{dm}^{-3} \mathrm{NaOH}$. The reaction gave the zeolite Na-A, which was characterized using the mineralogical (XRD, SEM-EDS, DTA/TG), chemical (XRF), and textural (ASAP) methods. XRD studies have shown that the obtained product is of high purity zeolite A wherein content of zeolite phase in the obtained material was $95 \%$ wt. The rest was a quartz. Grain morphology analysis (SEM) confirmed the good crystallization of zeolite, wherein the zeolite is formed by very well developed cubic crystals. The specific surface area (in textural analysis) determined under a nitrogen atmosphere was $4 \mathrm{~m}^{2} / \mathrm{g}$. The pore size distribution showed that the zeolite is a micro- and mesoporous with a dominant share of pores with a diameter of $3.5 \AA$. In order to determine the suitability of the tested zeolite material for the sorption of carbon dioxide, preliminary tests were carried out in order to determine the specific surface area in the $\mathrm{CO}_{2}$ atmosphere in the temperature of 0 and $25^{\circ} \mathrm{C}$. These studies gave surprising results, since the surface area in $\mathrm{CO}_{2}$ atmosphere for each tested temperatures was about $400 \mathrm{~m}^{2} / \mathrm{g}$. This result indicates very good selectivity of the obtained material with respect to $\mathrm{CO}_{2}$, therefore zeolite Na-A should be further analyzed to estimate their usefulness for carbon dioxide capture needs. The results of synthesis and characteristics of zeolite Na-A suggests the possibility of using domestic raw kaolin material for the preparation of high quality zeolite A. 
